University of Nebraska - Lincoln

DigitalCommons@University of Nebraska - Lincoln

1981

\title{
The Effects of MBO on Performance and Satisfaction in a Public Sector Organization
}

\author{
Kenneth R. Thompson \\ University of Notre Dame \\ Fred Luthans \\ University of Nebraska - Lincoln, fluthans1@unl.edu \\ Willbann D. Terpening \\ University of Notre Dame
}

Follow this and additional works at: https://digitalcommons.unl.edu/leadershipfacpub

Part of the Management Sciences and Quantitative Methods Commons

Thompson, Kenneth R.; Luthans, Fred; and Terpening, Willbann D., "The Effects of MBO on Performance and Satisfaction in a Public Sector Organization" (1981). Leadership Institute Faculty Publications. 22. https://digitalcommons.unl.edu/leadershipfacpub/22

This Article is brought to you for free and open access by the Leadership Institute at DigitalCommons@University of Nebraska - Lincoln. It has been accepted for inclusion in Leadership Institute Faculty Publications by an authorized administrator of DigitalCommons@University of Nebraska - Lincoln. 


\title{
The Effects of MBO on Performance and Satisfaction in a Public Sector Organization
}

\author{
Kenneth R. Thompson \\ University of Notre Dame \\ Fred Luthans \\ University of Nebraska \\ Willbann D. Terpening \\ University of Notre Dame \\ Corresponding author - Ken Thompson, Department of Management, \\ University of Notre Dame, Notre Dame, IN 46556
}

\begin{abstract}
This field study examined the effects of $\mathrm{MBO}$ on measures of quantity and quality of performance and satisfaction with the work and supervision among employees in a human services agency. Although not all the quantity measures improved significantly, the combined measure for quantity of performance and one of two quality measures showed significant improvement following implementation of MBO. Satisfaction with supervision also significantly improved but not satisfaction with work. The study lends support to the use of $\mathrm{MBO}$ in public sector organizations.
\end{abstract}

Management by objectives (MBO) has been advocated as a tool to improve management effectiveness for over twenty-five years. Drucker (1954) first advocated $\mathrm{MBO}$ as a systematic approach to setting objectives that would lead to improved organizational performance and employee satisfaction. A multitude of private sector business organizations and public sector organizations have implemented some form of MBO. A number of descriptive articles provide testimonials to the effectiveness of $\mathrm{MBO}$, but few comprehensive studies have tested these claims. Most of the MBO literature has focused on describing the technique, suggesting the steps for implementation, and listing the advantages and disadvantages of adopting an MBO program. For example, McConkie, (1979), has a comprehensive summary of thirty-nine experts' descriptions of the nature of $\mathrm{MBO}$.

\section{MBO-State of the Art}

This study analyzed changes in performance and employee satisfaction resulting from an $\mathrm{MBO}$ program in a state vocational rehabilitation agency. A review 
of the MBO literature shows that there are basically three types of research in the area. The first type examines the impact of $\mathrm{MBO}$ on employee satisfaction. The second focuses on the influence of MBO on performance as measured by subjects' perceptions. The third relates the $\mathrm{MBO}$ intervention to objective measures of performance. Additionally we have many anecdotal accounts of the effects of MBO satisfaction, but these studies will not be considered here.

Several studies have tested the effects of MBO upon satisfaction without examining performance. In a quasi-experimental study of 166 managers, Ivancevich, Donnelly, and Lyons (1970) found that need satisfaction improved in one company but not in another. Extending this study, Ivancevich (1972) found that the improvement in need satisfaction was short lived and disappeared 18-20 months after the initial intervention. Similarly, Tosi, Hunter, Chesser, Tarter, and Carroll (1976) found conflicting results when they surveyed two organizations, one under an MBO program $(n=117)$ and one not $(n=73)$. In general, there seems to be support for the premise that $\mathrm{MBO}$ programs lead to at least short-run satisfaction improvements.

Other research has focused on the relationship between $\mathrm{MBO}$, self-perceptions of performance, and satisfaction. Performance in these studies measured only subjects' perceptions of performance improvement; no objective measures of performance were made. Meyer, Kay, and French (1965) and French, Kay, and Meyer (1966) indicated that MBO improved satisfaction and performance, but no tests of significance were made and the definition of the criterion for performance was not indicated. Additionally, the second study found participative goal setting to be important to satisfaction and performance improvement if the respondent had a high need for autonomy. Steers (1975) found, through questionnaire data acquired from 133 female first level supervisors, that satisfaction and job involvement were enhanced by an MBO program. Steers (1975) identified goal specificity and need for achievement as important components of the improvement process. In a similar vein, other studies (Tosi \& Carroll, 1968, 1969, 1970, 1973; Shetty \& Carlisle, 1974a) have found support for associating MBO with satisfaction and performance improvements. Several of these studies, however, did not statistically test performance changes (Tosi and Carroll, 1968, 1969, and 1970) and none of the studies used a control group or examined changes longitudinally.

Studies that have used objective measures of performance include Raia (1965, 1966), Ivancevich (1974), and Muczyk (1978). Raia's studies reported a performance improvement but no statistical tests were used. Ivancevich (1974) used archival records to measure performance for two experimental groups and a control group. He found a statistically significant improvement in performance in one of the experimental groups but only directional support in the other. Ivancevich measured satisfaction through the use of the grievance rates at each of three plants. A significant increase in grievances was experienced. Muczyk (1978) evaluated $\mathrm{MBO}$ in a bank setting and over several performance measures found no statistically significant differences between the experimental and control groups.

In summary, the research seems to point toward improvements in perfor- 
mance and satisfaction resulting from an $\mathrm{MBO}$ intervention. The relationship for performance, however, has been less consistently found when objective measures rather than perceptual self-report data were used.

\section{Components of $\mathrm{MBO}$}

MBO involves the employee in participative goal setting. The goals become a form of feedback or knowledge of results. Latham and Yukl (1975) indicate these components in the process of goal setting. They are: (a) goal setting itself, (b) participation in goal setting, and (c) knowledge of results.

Goal setting itself is positively related to performance. Consistent and significant improvements in performance as a result of goal setting have been found in studies by Locke and others (Bryan \& Locke, 1967; Locke E Bryan, 1969; Locke, Cartledge \& Knerr, 1970; Locke, 1975; and Umstot, Bell \& Mitchell, 1976; and Ivancevich, 1977). Setting goals improves performance and the more difficult it is to reach the goals the better the performance, up to the point where goals are perceived as impossible (Stedry \& Kay, 1966; and Zander \& Newcomb, 1967). The relationship between goal setting and satisfaction is less clear. (See Arvey, Dewhirst \& Brown, 1978, for a review). Other variables seem to moderate the effects of goal setting on satisfaction.

Participation has mixed effects on performance. Effectiveness seems to depend on the amount and type of participation (Latham $\mathcal{E}$ Saari, 1979; and Euske $\mathcal{E}$ McFillen, 1979) and the individual (Steers, 1975 \& 1976; Ivancevich, 1979; and French, Israel, $\mathcal{E}$ As, 1960). Increased levels of participation lead to satisfaction improvements, although this relationship appears to depend on the needs of the employee (Steers, 1976).

Knowledge of results tends to increase performance levels, but the results are more apparent when it is tied to goal setting (Locke and Bryan, 1969; Nemeroff \& Consantio, 1979; Conlon, 1980) and the individual values (Braunstein, Klein, and Pachla, 1973; Latham and Baldes, 1975). Knowledge of results also improves satisfaction (Cook, 1968; Locke, 1965; Hackman \& Lawler, 1971; and Ilgen, 1971) although this relationship seems to be moderated by attributes of the individual.

In summary, goal setting aids performance and, to some degree, satisfaction. Participation and knowledge of results can aid performance and satisfaction but there are moderating variables that affect the results.

\section{$\mathrm{MBO}$ in the Public Sector}

As with private sector applications, a growing number of descriptive articles deal with MBO applications in the public sector (Brady, 1973; Malek, 1974; Morrisey, 1976; Jun, 1976; Knezevich, 1972; Luthans, 1976; Fri, 1974; McConkey, 1973; Luthans \& Sellentin, 1971). With the exception of several unpublished dissertations (Altergott, 1970; McConkie, 1977) and case studies (Hodgson, 1973; Shetty $\mathcal{E}$ Carlisle, 1974) no reported empirical research evaluates the impact of $\mathrm{MBO}$ on 
performance and satisfaction in public sector organizations. Further, the limited research on $\mathrm{MBO}$ in business organizations is difficult to generalize to public sector organizations. Newman and Wallender (1978) identified four major differences between public sector and private organizations:

(1) Service objectives are intangible and difficult to quantify and measure.

(2) Customer/client influence may be weak. Payment by customer/clients may be a nonexistent or secondary source of funds.

(3) Public employees often have more professional commitment than organizational loyalty.

(4) Resource contributors (fund contributors or the government) may intrude into internal management.

The main difference between public and private sector organizations is the two-party transactional relationship common to the former. The lack of an economic criterion to judge the effectiveness and efficiency of public sector organizations leads to difficulty in setting clear and direct goals and obtaining measures by which organizational performance can be assessed.

Despite these real and potential problems, $\mathrm{MBO}$ is frequently prescribed in the descriptive articles as a way to meet the accountability pressures facing public sector agencies and as a way to improve their performance and employee satisfaction. In addition, since the 1974 edict by Fred Malek, then the Director of the Office of Management and Budget, all federal agencies have been required to use some form of MBO in their programs (Malek, 1974; McCaffery, 1976). With this background, the present study was undertaken to evaluate the impact that MBO had on performance and satisfaction in one public sector agency.

Four hypotheses were tested in the study. The first two hypotheses concerned the efficacy of $\mathrm{MBO}$ in improving performance. The third and fourth hypotheses examined satisfaction with supervision and satisfaction with the work itself.

Hypothesis 1. $\quad$ MBO will improve the quantity of performance in a public sector agency.

Hypothesis 2. $\quad$ MBO will improve the quality of performance in a public sector agency.

Hypothesis 3. $\quad \mathrm{MBO}$ will improve the satisfaction of public sector employees with their supervision.

Hypothesis 4. $\quad$ MBO will improve the satisfaction of public sector employees with the work itself.

The goal of this study was not to provide new and unique measures of individual performance but rather to focus on measures that were already being employed in the organization. $\mathrm{MBO}$, as a program, should direct individual effort toward the attainment of organizational goals. To avoid any novelty effects resulting from the introduction of new performance measures, the measures used to analyze the impact of $\mathrm{MBO}$ were those for which archival data were available. 


\section{Method}

\section{Procedure and Subjects}

The study used three of the six regional offices of a state human services agency whose primary responsibility was to deliver vocational rehabilitation services. The experimental group consisted of one region. The other two regions were combined to form a control group. The MBO program involved two phases. The first was a training and development phase. Seven 21/2-hour training sessions were conducted by the researchers to provide supervisors with the background, philosophy, and specific steps for implementation of MBO. A fivestep MBO model (Odiorne, 1965) served as the framework for implementation. It consisted of setting overall objectives, preparation and development, individual objective setting between superior-subordinate pairs with accompanying action plans, periodic appraisals, and year-end review. The training stressed the writing of quantified behavioral objectives and the use of contingent social reinforcers (Luthans \& Kreitner, 1975) for progress attainment. All supervisory personnel in the regional office were involved. A total of twelve supervisors went through the training.

Phase Two of the MBO program consisted of in-depth individual counseling and interview sessions between the researchers and each supervisor to establish objectives for his or her department and for individual employees. Phase Two culminated with the regional director and each supervisor negotiating specific objectives for the upcoming year. Quarterly milepost objectives were stated for periodic review purposes. This phase was repeated each quarter throughout the study. The supervisor was then instructed to work with each of his or her staff members (counselors) to establish quantified, observable, measurable objectives. A total of twenty-three professional counselors were involved in this $\mathrm{MBO}$ process. These counselors received a general orientation on MBO but received neither the intense training nor individual counseling that was given their supervisors.

Measures of quantity performance were taken for the experimental and control groups on a monthly basis for nine months before and 18 months after the implementation of MBO. Measures of quality performance were unavailable for the control group because of region-by-region variance in record keeping. The researchers were able to obtain satisfaction measures for the experimental group only and just at two times (pre- and post-implementation). Because the control group did not participate in the satisfaction survey, no reactive effect on the control group's performance measures was obtained from archival data.

The control group, taken from two regions, consisted of twenty-three counselors, all in the same state system. The control group was matched as closely as possible with the experimental group as to work experience and educational background, and in terms regional demographics. Both the control group and the experimental group served the same types of populations and had similar re- 
sponsibilities. The supervisors of the control group averaged approximately 10 years with $t^{*}$ e organization and 6 year" as supervisors; the experimental group averaged 8 years with the organization and 4 years as supervisors. All supervisors and counselors had undergraduate college degrees. Graduate degrees were held by 12 of the 2 counselor" in the control group .and 14 of the 23 counselors in the experimental group. Al) the supervisors, in the control group had graduate degrees. The average length of service for counselors was 5 and 4 years for the control and experimental groups respectively.

\section{Measures}

The dependent .variables were four measures of the performance quantity, two measures of the performance quality, and two measures of satisfaction. The quantity measures were part of a report that each supervisor received monthly. These quantitative measures were based on a sample of what the director and supervisors agreed represented overall performance measures for their staff of counselors. Briefly summarized, they were the following:

1. Referrals. The amount of contacts in the field that a counselor made toward finding vocational rehabilitation clients - this helped increase the number of referrals that the individual counselor received. Referrals were the names of potential clients that the counselor received over a period of one month.

2. Acceptances. According to federal regulations, a person must pass an eligibility test in order to qualify for services. This acceptance test involved several operations by the counselor in terms of paperwork and/or calls with several agencies.

3. Plans written. Once a client was accepted, the counselor would write a behavioral, objective plan for rehabilitation. If the client decided to change programs, a new plan would be written. Plans written, therefore, were activities by the counselor toward completing the program of the client.

4. Rehabilitations. Once the client passed through the rehabilitation program and found employment for sixty continuous workdays, the counselor could consider the individual rehabilitated. Rehabilitations made were a good indication of the activity of the counselor in insuring that the individual progressed through the program and was successfully placed.

An overall measure of quantity of performance was calculated by simply combining measures one through four above.

After considerable discussion with the director and the supervisors, two quality measures of performance were identified. Both items measured the number of errors made in the completion of a client's casework. One measure included the number of errors that a counselor made with respect to the computerized case 
form (CCSR). The second measure was the number of errors made on the client $\mathrm{s}$ billing codes for funds disbursement. These latter errors were called financial edit errors. A combined index of overall performance quality was calculated by combining both the CCSR and financial errors. While these measures do not represent comprehensive measures of the quantity and quality of a counselor's work, they do represent important dimensions of overall performance. Importantly, the quality and quantity measures used in the evaluation were from existing informational records available to all employees. Such use of archival data minimizes the reactive effects of the data gathering (Webb, Campbell. Schwartz, \& Sechrest, 1960).

The satisfaction measures were obtained through the Job Description Index (Smith, Kendall, \& Hulin. 1969). Only the satisfaction with, supervision and work scales of the JDI were utilized in this study. Satisfaction was measured twice, 6 months before and 12 months after the MBO intervention.

\section{Results}

\section{Quantity Measures}

The first hypothesis was that MBO will improve the quantity of performance. This implies that performance quantity should increase for the experimental group (MBO intervention) relative to the control group (no MBO intervention). The effectiveness of the MBO intervention can be shown either if the experimental group performance increases following intervention while control group performance does not, or if the performance increase in the experimental group is significantly greater than any performance increase in the control group. In statistical terms, this hypothesis implies a statistically significant interaction between the experimental factors of region (experimental vs. control) and time. A significant interaction indicates that the relative performance levels of the two groups have changed while being controlled for any pre-experimental performance differences. This hypothesis can be tested via the general linear model where region is a dichotomous factor and time is a continuous variable. The SAS statistical package was used for this analysis. Table I indicates that significant interactions were found for referrals, acceptances, and the combined measure.

Table 1. Quantity Measures of Performance: Global Test for Interaction Between Regions and Time

\begin{tabular}{lccc}
\hline VARIABLE & $\begin{array}{c}\text { REGION } \\
\mathrm{F}(\mathrm{df}=1,1049)\end{array}$ & $\begin{array}{c}\text { TIME } \\
\mathrm{F}(\mathrm{df}=\mathrm{LI} 049\end{array}$ & $\begin{array}{c}\text { RxT INTERACTION } \\
\mathrm{F}(\mathrm{df}=1.1049)\end{array}$ \\
\hline Referrals & $31.11^{* *}$ & .01 & $15.38^{* *}$ \\
Acceptances & $5.98^{*}$ & $29.43^{* *}$ & $4.10^{*}$ \\
Plans & 2.67 & $56.91^{* *}$ & 2.47 \\
Rehabilitations & $9.22^{* *}$ & 2.21 & .01 \\
Combined Measures & $39.76^{* *}$ & $13.22^{* *}$ & $17.88^{* *}$ \\
\hline
\end{tabular}

${ }^{*} \mathrm{p}<.05 ;{ }^{* *} \mathrm{p}<.01$ 
Table 2. Quantity Measures of Performance: Significant Trend Analysis

\begin{tabular}{lcc}
\hline Variable & Pre-intervention & Post-Intervention \\
\hline Experimental Group & $\mathrm{t}(\mathrm{df}=1.169)$ & $\mathrm{t}(\mathrm{df}=1,178)$ \\
Referrals & .71 & $2.87^{* *}$ \\
Acceptances & -.34 & $2.39^{*}$ \\
Plans & -1.12 & $3.18^{* *}$ \\
Rehabilitations & -.92 & .10 \\
Combined Measures & -.27 & $4.09^{* *}$ \\
Control Group & $\mathrm{t}(\mathrm{df}=1.340)$ & $\mathrm{t}(\mathrm{df}=1.358)$ \\
Referrals & $-2.12^{*}$ & 1.91 \\
Acceptances & -.23 & 1.70 \\
Plans & .09 & 1.61 \\
Rehabilitations & $2.82^{* *}$ & .20 \\
Combined Measures & -1.61 & $2.61^{* *}$ \\
\hline
\end{tabular}

${ }^{*} \mathrm{p}<.05 ;{ }^{* *} \mathrm{p}<.01$

The nature of these global interaction effects can be examined by looking at the trend for performance measures within each region. The trend in performance across time was assessed within each region both before and after the MBO intervention by regressing the performance measures on the time factor. These results are presented in Table 2. There were no significant trends for any of the quantity measures for the experimental group in the pre-intervention period. For the control group there was a significant negative trend for referrals and a significant positive trend for rehabilitation. The other two individual measures and the combined measure showed no significant trends for the control group. The significant negative trend in referrals was due to an extremely low number of referrals in the last month of the pre-intervention period. If this month were not included in the analysis, only the positive trend in rehabilitations would be statistically significant.

In contrast to the pre-intervention period, the trend analysis for the experimental group in the post-intervention period showed a significant positive trend for all measures except rehabilitation. Thus, four of the five measures that showed no tendency toward improved performance before the MBO intervention showed such a tendency after the intervention. The analysis of the post-intervention period for the control group found that none of the trends for the four individual measures was significant, although the combined measure showed a significant positive trend.

The pattern of performance over time can be seen in Figure 1, which plots the monthly averages for the combined measure by region. This figure clearly shows that the extreme observation for the control group in the ninth month influenced the trend estimate in the pre-intervention analysis. Note also the downward drift in the pre-MBO intervention period (month one to month nine). After the MBO intervention, the differences between groups become negligible compared to the pronounced differences before the intervention. Also, the difference between regions decreases before, compared with 18 months after, the MBO intervention. 


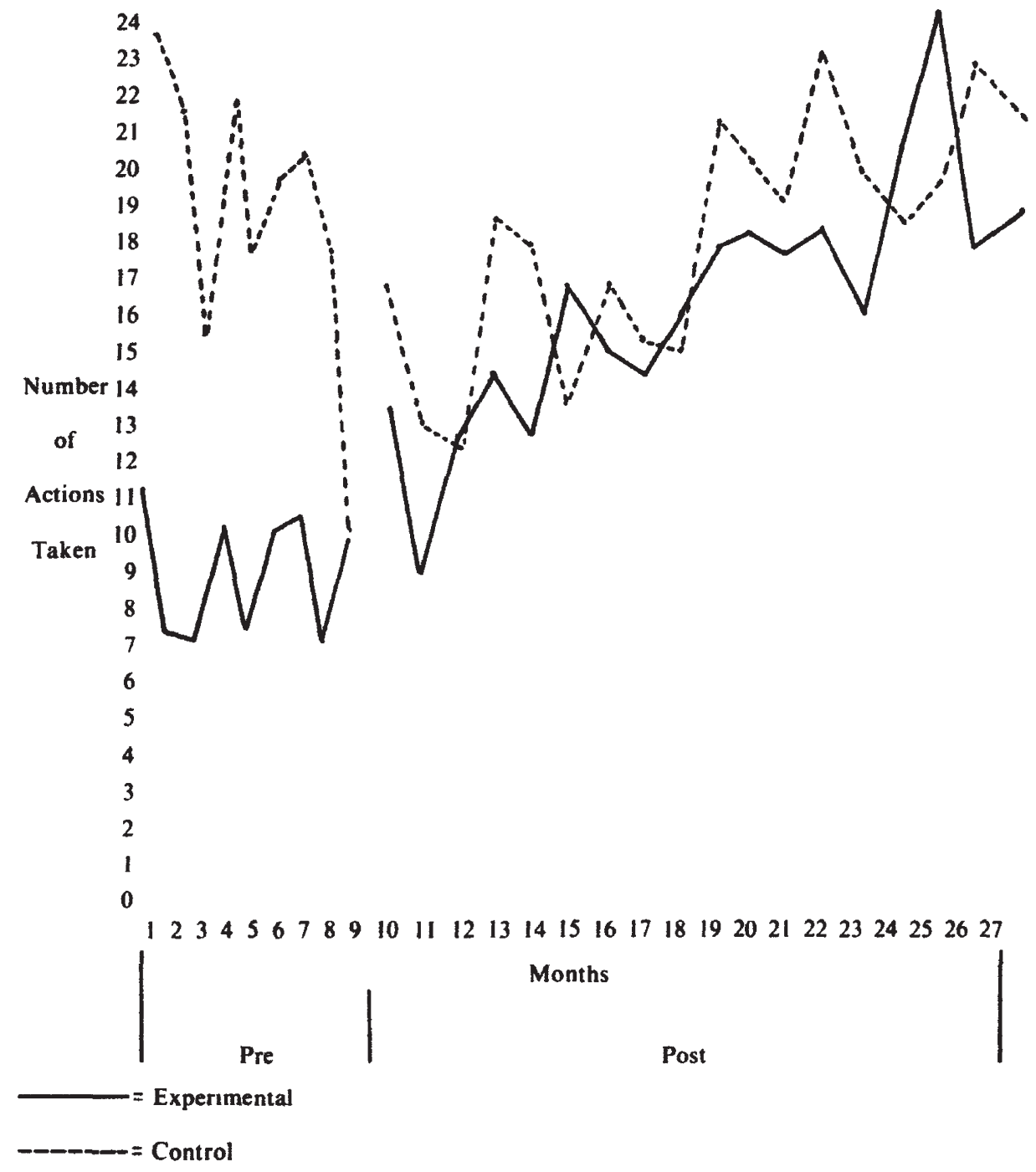

Figure 1. Plot of Means of Combined Measure of Average Counselor Performance

\section{Quality Measures}

Hypothesis two is that the initiation of MBO will improve the quality of performance. In the present case, quality was measured by errors made in the completion of the casework so that this hypothesis predicted a negative trend in the quality measures following the $\mathrm{MBO}$ intervention. Because quality measures were only available for the experimental group, this hypothesis was tested by simple trend analysis both preceding and following the intervention. The results are presented in Table 3. Significant negative trends were observed in the pre-intervention period for the CCSR and combined error rates. The financial edit errors showed no significant trend. In the post-intervention period the CCSR er- 


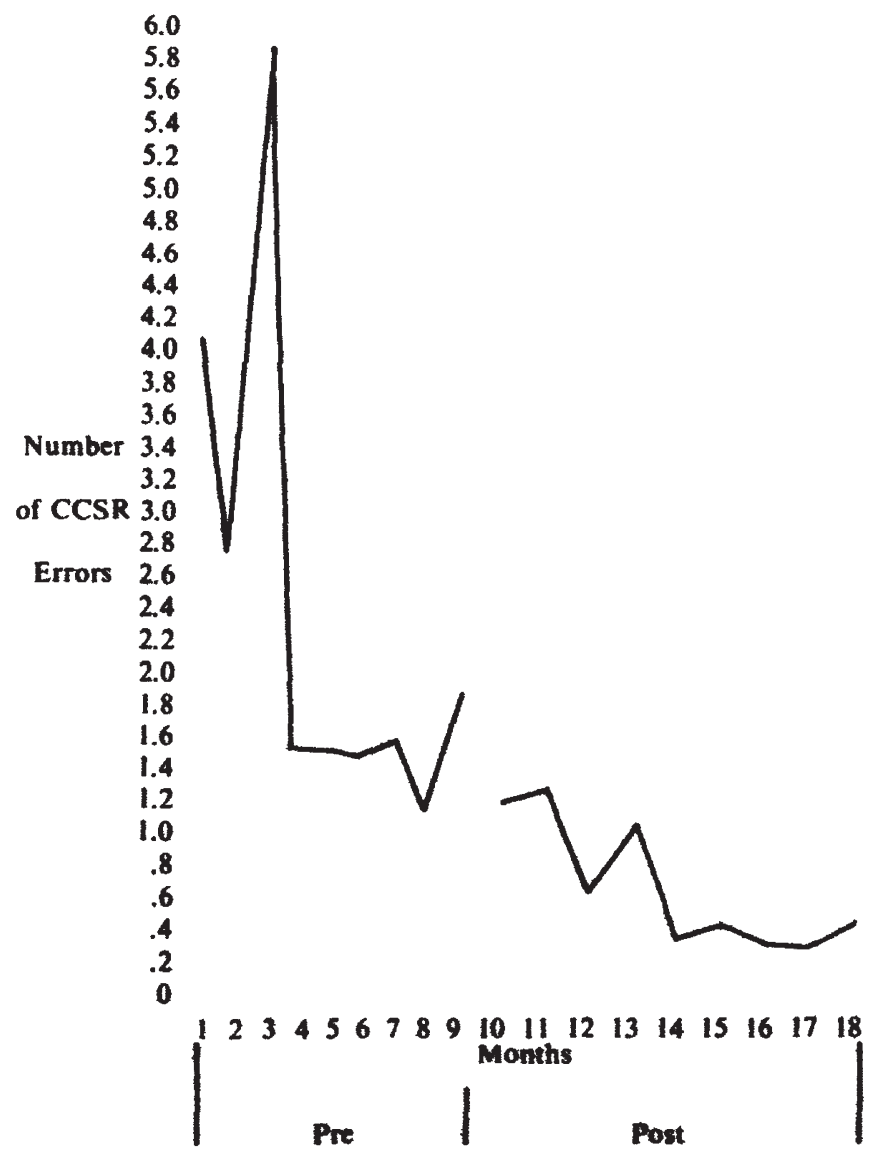

Figure 2. Plot of Means of Average Monthly CCSR Errors Per Customer

ror rate indicated a further significant negative trend with the other trends being insignificant. The monthly averages for the CCSR errors are plotted in Figure 2. In the pre-intervention period the error rate appeared to drop about the fourth month and then level off. In the post-intervention period there was a further drop in the error rate. The potential magnitude of this trend was greatly impaired by a floor effect, i.e., by the fact that the error rate cannot be less than zero.

Table 3. Quality Measures of Performance Trend Test

\begin{tabular}{lcc} 
VARIABLE & \multicolumn{2}{c}{ TREND TEST } \\
& $\mathrm{PRE}$ & $\begin{array}{c}\text { POST } \\
\mathrm{t}(\mathrm{df}=170)\end{array}$ \\
\hline CCSR $(\mathrm{df}=170)$ \\
Financial Edit & $-3.79^{* *}$ & $-2.57^{* *}$ \\
Combined & -.75 & -.21 \\
${ }^{*} \mathrm{p}<.05 ;{ }^{* *} \mathrm{p}<.01$ & $-2.17^{*}$ & -1.29 \\
\hline
\end{tabular}




\section{Satisfaction Measures}

Hypotheses three and four were that the MBO intervention will improve employee satisfaction with both supervision and the work itself. Satisfaction measures were obtained both before and after the intervention. Satisfaction with work did increase following the intervention but the increase was not statistically significant $(\bar{x}=32.82$ pre, 36.59 post; $t=1.56)$. Satisfaction with supervision, however, showed a significant improvement following the intervention $(\bar{x}=36.73$ pre, 45.91 post; $\mathrm{t}=4.69, \mathrm{p}<.01)$.

\section{Discussion}

The results of this study generally suggest that MBO improved performance in the public sector organization studied. This finding is consistent with Ivancevich's (1974) study conducted in a private sector organization. The prediction that quantity of performance would improve following the MBO intervention was supported by significant improvements in three out of four archival performance measures and in the combined overall measure of performance following the intervention. There were no significant trends on any of the five measures prior to the MBO intervention period. The graph of means over the twenty-seven month period supports the positive trend in the overall measure of performance of the experimental group. This positive trend occurred directly after the intervention period. The graph indicates some other general considerations that merit attention. Although there was a large difference between the control and experimental groups from month 1 until month 9 (the pre-intervention period), after the MBO intervention the control and experimental groups were similar in levels of performance.

In comparing results for the experimental and control groups, it is important to examine the pattern of results for the control group prior to the intervention. In period nine the average performance level for the control group was radically different from that of the previous eight periods. The sharp drop in performance in period nine can be attributed to either a continued significant downward trend in performance (as indicated by the slopes in Table 2) or the existence of some other causal factor. Discussions with the regional directors of all three groups (one experimental group and two control group regions) revealed that the period nine results reflect the various regions' activities at the end of the fiscal year. The control group's counselors had completed cases for the particular fiscal year and did not want to start new cases. This factor, however, did not seem to affect the experimental group. It was not unusual to encounter work fluctuations such as these in caseload statistics at the beginning or ending of a fiscal year because at these times the individual counselors attempt to "clean house" of their caseloads. It seems more likely, therefore, to attribute the control group's downturn trend in period nine to the end-of-the-year situation rather than to a strong downshift in performance. It should be noted, however, that national caseload statistics for Vocational Rehabilitation Agencies showed a mild downward trend 
(National Rehabilitation Counseling Association, 1976). Both the control and experimental groups seem to reflect this trend in the pre-intervention period, as can be seen in Figure 1.

Several alternative explanations of the performance changes might be considered, especially in light of the differences between groups before the intervention. The results might represent a regression toward the mean, or just the counselors' perceptions that management was becoming more concerned with caseload statistics. The argument that the performance of the counselors was regressing toward a mean cannot be discounted entirely, but there was strong reason to believe that this was not the case. The trends and the consistency of the data over the 27 month period strongly suggested that the performance changes seen in the experimental group resulted from the intervention. Graphically this was demonstrated by the marked changes in the average monthly performance after the intervention period and also by the absence of a trend before the intervention and the presence of a significant positive trend after the intervention. Had regressions toward the means been a factor, changes should have been evident both before and after the intervention.

It should be noted that there was also a significant upward trend in the control group's overall measure of performance after intervention, although this rate of performance improvement was less than that of the experimental group (slope of experimental, post-intervention $=.373$ vs. .326 of the control group). The upward trend in performance for the control group can be attributed to management's increased awareness of individual counselor performance. This might have been the result of a contamination effect of the MBO study on the control group or increased concern at the state level for performance improvement. While attempts were made to reduce the impact of the MBO intervention on the control groups, this is not always possible in organizational settings. The control group, however, was located in a separate region, hence the contamination effect should have been minimized.

\section{Quality Measures}

The results were inconsistent with respect to the hypothesis that an MBO intervention will lead to an improvement in the quality of performance. The significant negative trend in the combined and the CCSR error rates indicated that the error rate was already on a downward trend before the institution of the MBO program. The continued significant downward trend of the CCS R rate after the intervention could be attributable to either the $\mathrm{MBO}$ approach or to a continuation of the existing downward slope indicated before the intervention. In retrospect, the reduction of the error rate may again have related to the emphasis of management on the collecting and reporting of the error data. Although this was existing information available to all counselors and managers alike, there may have been a contamination effect resulting from the decision to include the data in the MBO study. This decision was made at the beginning of the pre-interven- 
tion measurement period. Although this was not generally indicated to the individual counselors, the message may have been received through informal discussions between management and staff. The change in error rates, therefore, could not readily be attributed to the MBO intervention alone. It is important, however, to recognize that the increase in quantity of performance was more likely to lead to an increase rather than a decrease in errors. That this did not happen suggests that $\mathrm{MBO}$ might have had some impact on quality of performance.

\section{Satisfaction Measures}

The results of the satisfaction questionnaire were mixed. Satisfaction with supervision significantly increased after implementation of the MBO program (hypothesis three) and there was directional (but not significant) support that work satisfaction improved (hypothesis four). These results are consistent with previous research (Steers, 1976; Tosi et al., 1976). There seems to be some support for the hypothesis that MBO leads to a satisfaction improvement, at least over the short term (Ivancevich, 1976). Reliance on these results must be tempered, however, because a control group was not available and only two measurements were taken (before and after) in assessing changes in satisfaction. Formal and informal interviews indicated that the employees were satisfied with their ability to participate and formulate some specific objectives.

Several limitations of this study need to be stressed. First, the conclusion based on the quality data should be interpreted with caution because the quality measures sampled only the correct completion of paperwork and therefore were not a comprehensive measure of the quality of a counselor's performance. Second, the sample size for this study was relatively small. Because a high degree of variability was found in the data, it would be beneficial to replicate this study on larger and different populations. Finally, both the satisfaction and the quality measures were obtained from the experimental group only. Greater confidence in the results might be warranted if a control group had been available for these measures. It would also be interesting to measure satisfaction over several periods of time instead of for one pre- and one post-intervention. The longevity of the effects on satisfaction were not measured as had been done in the Ivancevich (1972) study (finding MBO satisfaction improvements to be short-lived). Further study and research are needed on the effects that MBO has upon quantity and quality of performance and employee satisfaction.

The limitations inherent in field experiments notwithstanding, this study suggests MBO may have a favorable impact on performance and satisfaction in public sector agencies. MBO seems to be effective even within the confining restrictions of the highly structured but vague organizational objectives of government agencies. The essence of an effective MBO program at any level entails providing for observable, measureable indices of performance. Reinforcement of the MBO process and continuous reinforcement while using the system aids in its acceptance and use. 


\section{References}

Altergott, B. H. Management by objectives for the public schools. Doctoral dissertation, Indiana University, 1970.

Arvey, R. D., Dewhirst, H. D., \& Brown, E. M. A longitudinal study of the impact of changes in goal setting on employee satisfaction. Personnel Psychology, 1978, 31, 595-608.

Brady, R. M. MBO goes to work in the public sector. Harvard Business Review, 1973, 51, 65-74.

Braunstein, D. N., Klein, G. A., \& Pachula, M. Feedback expectancy and shifts in student ratings of college faculty. Journal of Applied Psychology, 1973, 58, 254-258.

Bryan, J. F. \& Locke, E. A. Goal setting as a means of increasing motivation. Journal of Applied Psychology, 1967, 56, 274-277.

Carroll, S. J. \& Tosi, H. L. Management by objectives: Applications and research. New York: The Macmilian Co., 1973.

Conlon, E. J. Feedback about personal and organizational outcomes and its effect on persistence of planned behavioral changes. Academy of Management Journal, 1980, 23, 267-286.

Cook, D. M. The impact on managers of frequency of feedback. Academy of Management Journal, 1968, 11, 263-277.

Drucker, P. The practice of management. New York: Harper \& Row, 1954.

Euske, K. \& McFillen, J. Satisfaction and performance implication of employee performance for and control over measures used in performance evaluation. Ohio State Work Paper Series 79-13. Columbus: College of Administrative Science, The Ohio State University, 1979.

French, Jr., J. R. P., Israel, J., \& As, D. An experiment on participation in a Norwegian factory. Human Relations, I960, 13, 3-19.

French, Jr., J. R. P., Kay, E., \& Meyer, H. H. Participation and the appraisal system. Human Relations, 1966, 19, 3-19.

Fri, R. W. How to manage the government for results: The rise of MBO. Organizational Dynamics, 1974, 4, 19-33.

Hackman, J. R. \& Lawler, E. E. Employee reactions to job characteristics. Journal of Applied Psychology, 1971, 55, 259-286.

Hodgson, J. S. Management by objectives: The experience of a federal government department. Canadian Public Administration, 1973, 16, 422-431.

Ilgen, D. R. Satisfaction with performance as a function of the initial level of expected performance and the deviations from expectations. Organizational Behavior and Human Performance, 1971, 6, 345-361.

Ivancevich, J. M. A longitudinal assessment of management by objectives. Administrative Science Quarterly, 1972, 17, 126-138.

Ivancevich, J. M. Changes in performance in a management by objectives program. Administrative Science Quarterly, 1974, 19, 563-574.

Ivancevich, J. M. An analysis of participation in decision making among project engineers. Academy of Management Journal, 1979, 22, 253-269.

Ivancevich, J. M., Donnelly, J. H., \& Lyons, H. L. A study of the impact of management by objectives on perceived need satisfaction. Personnel Psychology, 1970, 23, 139-151.

Jun, S. A symposium: Management by objectives in the public sector. Public Administration Review, 1976, 36, 1-5. 
Knezevich, S. J. MBO: Its meaning and application to educational administration. Education, 1972, 93, 12-21.

Latham, G. \& Baldes, J.J. The practical significance of Locke's theory of goal setting. Journal of Applied Psychology, 1975, 60, 122-124.

Latham, G. P. \& Saari, L. M. The effects of holding goal difficulty constant on assigned and participatively set goals. Academy of Management Journal, 1979, 23, 163-168.

Latham, G. P. \& Yukl, G. A review of research on the application of goal setting in organizations. Academy of Management Journal, 1975, 18, 824-846.

Locke, E. A. The relationship of task success to task liking and satisfaction. Journal of Applied Psychology, 1965, 49, 379-385.

Locke, E. A. Personnel attitudes and motivation, In M. R. Rosenzweig \& L.W. Porter (Eds.). Annual Review of Psychology. Palo Alto. Calif.: Annual Reviews. 1975.

Locke, E. A. \& Bryan, J. F. The directing functions of goals in task performance. Organizational Behavior and Human Performance. 1969. 4. 35-42.

Locke. E. A.. Cartledge, N., \& Knerr. C. S. Studies on the relationship between satisfaction, goal setting and performance. Organizational Behavior and Human Performance. 1970, 5, 135-158.

Luthans, F. Management by objectives in the public sector: The transference problem. Paper given at the Academy of Management Annual Meeting, 1975.

Luthans, F. How to apply MBO. Public Personnel Management. 1976, 5, 83-87.

Luthans, F. \& Kreitner, R. Organizational behavior modification. Glenview, 111.: Scott, Foresman \& Co., 1975.

Luthans, F. \& Sellentin. J. L. MBO in hospitals: A step toward accountability. Personnel Administrator, 1976, 21. 42-45.

Malek, F. Managing for results in the federal government. Business Horizons. 1974, 17, 23-28.

McCaffery, J. MBO and the federal budgetary process. Public Administration Review. 1976. $36,33-40$.

McConkey. D. D. Applying management by objectives to non-profit organizations. SA M Advanced Management Journal, January, 1973, pp. 10-25.

McConkie, M. L. Management by objectives in the public sector: Defining the concept and testing its application. Doctoral dissertation. University of Georgia, 1977.

McConkie. M. L. A clarification of the goal setting and appraisal process in MBO. Academy of Management Review, 1979, 4, 29-40.

Meyer, H., Kay, E., \& French, J. R. P. Split roles in performance appraisal. Harvard Business Review, 1965, 43, 123-129.

Morrisey, G. L. MBO questions and answers. Public Personnel Management, 1976, 5, 96- 102.

Muczyk, J. P. A controlled field experiment measuring the impact of MBO on performance data. Journal of Management Studies, 1978, 15, 318-329.

National Rehabilitation Counseling Association. Memorandum: Statistical data on number of rehabilitations through August 31, 1976. November 22, 1976, p. 1.

Nemeroff, W. F. A Cosentino, J. Utilizing feedback and goal setting to increase performance appraisal interviewer skills of managers. Academy of Management Journal. 1979, 23, 566-576.

Newman, W. H. \& Wallender, H. W. Managing not-for-profit enterprises. Academy of Management Review. 1978, 3, 42-51. 
Odiorne, G. S. Management by objectives: A system of management leadership. New York: Hickman Publishing Corp., 1965.

Raia, A. P. Goal setting and self-control: An empirical study. Journal of Management Studies, 1965, 2, 32-53.

Raia, A. P. A second look at management by goals and controls. California Management Review, 1966, 8, 49-58.

Shetty, Y. K. \& Carlisle, H. M. Organizational correlates of a management by objectives program. Academy of Management Journal, 1974a, 17, 155-159.

Shetty, Y.K. \& Carlisle, H.M. Application of management by objectives in a University setting; and exploratory study in faculty reaction. Educational Administration Quarterly, 1974b, 10, 65-81.

Smith, P. C , Kendall, L. M.,\& Hulin, C. L. The Management of satisfaction in work and retirement. Chicago: Rand McNally, 1969.

Stedry, A. C. \& Kay, E. The effects of goal difficulty on performance. Crontonville, N.Y.: General Electric Co., Behavioral Research Service, 1966.

Steers, R. M. Task-goal attributes, in achievement, and supervisory performance. Organizational Behavior and Human Performance. 1975, 13, 392-403.

Steers, R. Factors affecting job attitudes in a goal setting environment. Academy of Management Journal. 1976, 19. 6-16.

Tosi, H. L. \& Carroll. S. J. Managerial reaction to management by objectives. Academy of Management Journal. 1968, 11, 415-426.

Tosi, H. L. \& Carroll, S. J. Some structural factors related to goal influence in the management by objectives process. MSU Business Topics. 1969, 17, 45-50.

Tosi, H. L. \& Carroll. S. J. Some factors affecting the success of management by objectives. Journal of Management Studies. 1970, 7, 209-223.

Tosi, H. L. \& Carroll, S. J. Improving management by objectives: A diagnostic change program. California Management Review. 1973, 16, 57-66.

Tosi. H. L., Hunter, J.. Chesser, R., Tarter, J. R., \& Carroll, S. J. How real are changes induced by management by objectives? Administrative Science Quarterly. 1976, 21, 276-302.

Umstot. D. D., Bell. C. H., \& Mitchell, T. R. Effects of job enrichment and task goals on satisfaction and productivity: Implications for job design. Journal of Applied Psychology. 1976, 61, 379-394.

Webb, E. J., Campbell. D. T., Schwartz, R. D., \& Sechrest, L. Unobtrusive measures: Nonreactive research in the social sciences. Chicago: Rand McNally, 1966.

Zander. A. \& Newcomb, T. T., Jr. Group levels of aspiration in United Fund campaign. Journal of Personality and Social Psychology. 1967, 6, 157-162. 